\title{
Health-related quality of life in infertile couples receiving IVF or ICSI treatment
}

\author{
Batool Rashidi ${ }^{1}$, Ali Montazeri*2,3, Fatemeh Ramezanzadeh ${ }^{1}$, \\ Mamak Shariat ${ }^{1}$, Nasrin Abedinia $^{1}$ and Mahnaz Ashrafi ${ }^{4}$
} \author{
Scotland, UK and ${ }^{4}$ Royan Institute, Tehran, Iran \\ Email: Batool Rashidi - bhrashidi@tums.ac.ir; Ali Montazeri* - montazeri@acecr.ac.ir; \\ Fatemeh Ramezanzadeh - fa_ramezanzadeh@yahoo.com; Mamak Shariat - shariat_soufi@yahoo.com; \\ Nasrin Abedinia - abedinia_nasrin@yahoo.com; Mahnaz Ashrafi - m.ashrafi@royan.org \\ * Corresponding author
}

Address: ${ }^{1}$ Vali-e-Asr Reproductive Health Research Center, Tehran University of Medical Sciences, Tehran, Iran, ${ }^{2}$ Iranian Institute for Health Sciences Research, Tehran, Iran, ${ }^{3}$ Public Health and Health Policy, Division of Community-Based Sciences, University of Glasgow, Glasgow,

Published: 19 September 2008

BMC Health Services Research 2008, 8:186 doi:10.1 186/1472-6963-8-186
Received: 28 May 2008

Accepted: 19 September 2008

This article is available from: http://www.biomedcentral.com//472-6963/8//86

(C) 2008 Rashidi et al; licensee BioMed Central Ltd.

This is an Open Access article distributed under the terms of the Creative Commons Attribution License (http://creativecommons.org/licenses/by/2.0), which permits unrestricted use, distribution, and reproduction in any medium, provided the original work is properly cited.

\begin{abstract}
Background: Infertile couples might experience psychological distress and suffer from impaired health-related quality of life. This study aimed to examine health-related quality of life in infertile couples receiving either in-vitro fertilization (IVF) or intracytoplasmic sperm injection (ICSI) treatment.

Methods: This was a cross-sectional study of quality of life in infertile couples attending to Vali-eAsr Reproductive Health Research Center or Royan Institute for either IVF or ICSI treatment in Tehran, Iran. Health-related quality of life was assessed using the Short Form Health Survey (SF36). Patients' demographic and clinical characteristics were also recorded. Data were analyzed to compare quality of life in infertile women and men and to indicate what variables predict quality of life in infertile couples.
\end{abstract}

Results: In all 5 I 4 women and $5 \mid 4$ men $(n=1028)$ were studied. There were significant differences between women and men indicating that male patients had a better health-related quality of life. Also health-related quality of life was found to be better in infertility due to male factor. Performing logistic regression analysis it was found that female gender, and lower educational level were significant predictors of poorer physical health-related quality of life. For mental health-related quality of life in addition to female gender and lower educational level, younger age also was found to be a significant predictor of poorer condition. No significant results were observed for infertility duration or causes of infertility either for physical or mental health-related quality of life.

Conclusion: The findings suggest that infertility duration or causes of infertility do not have significant effects on health-related quality of life in infertile couples. However, infertile couples, especially less educated younger women, are at risk of a sub-optimal health-related quality of life and they should be provided help and support in order to improve their health-related quality of life. 


\section{Introduction}

Infertility is a major life crisis [1]. Infertility can cause depression, anxiety, social isolation and sexual dysfunction $[2,3]$. Due to this frustrating experience many infertile couples would seek medical help and finally will receive assisted reproductive treatment [4]. According to patients' conditions most patients receive in-vitro fertilization (IVF) or intracytoplasmic sperm injection (ICSI) treatment. Most couples that plan to have treatment experience extensive and emotionally challenging methods of diagnosis and treatment. Often, their treatment options are limited and the procedures are considered by many couples to be the end of the line. People who seek treatment for infertility have been reported to be more anxious and emotionally distressed than people in the general population [5]. It is still not clear whether this elevated level of distress occurs in all couples planning to undergo infertility treatment or certain sub-groups may have more problems. It is likely, for instance, that infertility has a different impact on young people than on relatively older people planning to undergo treatment since for such couples treatment might be their last chance of having a baby [6]. In addition, factors that predicting quality of life may vary in different infertile populations, different gender and different ethnic backgrounds. Thus, the identification of factors associated with better or worse health-related quality of life is vital in order to propose and test scientifically based interventions for infertile populations [7].

Despite the existence of an extensive body of the literature on psychological aspects of the infertility, there are quite a few studies on health-related quality of life in infertile couples. A review of literature indicated that since 1982 to 2008 there were about ten studies that focused on healthrelated quality of life in infertile couples. [8]. This study aimed to contribute to existing knowledge and shad more light on the topic by reporting from a developing country where infertility might cause several social problems for infertile couples especially for women [9].

\section{Methods}

\section{Design and data collection}

From March 2006 to July 2006 all infertile couples attending to Vali-e-Asr Reproductive Health Research Center or Royan Institute for IVF or ICSI treatment were asked to participate in this prospective, cross sectional survey. A total of 1028 patients (514 women, 514 men) were entered into the study. Couples completed the questionnaire separately in the hospital setting at the time of their first clinical visits at the same point in the process of treatment.

\section{Measures}

Health-related quality of life was measured using the Short Form Health Survey-SF-36 [10]. The SF-36 includes eight subscales, and scores on each subscale range from zero to 100 indicating worse to better conditions respectively. The eight subscales are: Physical functioning (10 questions), Role physical (4 questions), Role emotional (3 questions) Pain (2 questions), Vitality (4 questions) General health (5 questions), Social functioning (2 questions), and Mental health (5 questions). The SF-36 provides two summary scores: physical component summary (PCS) and mental component summary (MCS). The psychometric properties of the instrument are well documented [11].

In addition, demographic and clinical characteristics of patients including age, gender, education, duration of infertility, previous treatment for infertility and infertility causes were also collected.

\section{Analysis}

Descriptive analyses were carried out to explore the data. The distributions of the health-related quality of life scores were examined. The scores were slightly skewed but all skewness values (except for physical functioning) were less than one allowing for using parametric tests. Statistical procedures included chi-square test for categorical data and t-test and one-way analyses of variance (ANOVA) for continuous data to compare the differences between the study sample subgroups. Logistic regression analysis was preformed to examine the predictive value of independent variables studied. For the purpose of analysis we used the physical component summary (PCM) and mental component summary (MCS) scores and relative to the mean score, patients were divided into two groups those who scored equal or higher than mean and those who scores lower than mean. The analysis was adjusted for the variables studied.

\section{Ethics}

The ethics committee of Tehran University of Medical Sciences approved the study. All patients gave consent for the study.

\section{Results}

In all, 1028 male and female were entered into the study. The mean age of woman was 31.4 years $(S D=5.9)$ and for men it was 35.9 years $(S D=6.0)$. Table 1 gives an overview of the main characteristics of the study sample.

The SF-36 scores for females and males are shown in Table 2. Comparing males and females it was found that male significantly scored higher, indicating to have a better health-related quality of life.

The health-related quality of life scores by infertility causes are shown in Table 3 . There were significant differ- 
Table I: The characteristics of the study sample

\begin{tabular}{|c|c|c|c|}
\hline & Male $(n=5 \mid 4)$ & Female $(n=514)$ & $P\left(\chi^{2}, d f\right)$ \\
\hline & No. (\%) & No. (\%) & \\
\hline Age groups (years) & & & $<0.001(117.2,3)$ \\
\hline$<25$ & $3(0.6)$ & $65(12.6)$ & \\
\hline $25-30$ & $98(19.0)$ & $180(35.0)$ & \\
\hline $31-35$ & $156(30.4)$ & $128(25.0)$ & \\
\hline$>35$ & $257(50.0)$ & |4| (27.4) & \\
\hline Mean (SD) & $35.9(6.0)$ & $31.4(5.9)$ & \\
\hline Educational status (years) & & & $0.21(3.09,2)$ \\
\hline$\leq 5$ (primary) & $142(27.6)$ & $157(30.5)$ & \\
\hline $6-12$ (secondary) & $193(37.5)$ & $204(39.7)$ & \\
\hline$>12$ (higher) & $179(34.8)$ & $153(29.8)$ & \\
\hline Duration of infertility (years) & & & $0.99(0.017,2)$ \\
\hline$\leq 5$ & $177(34.4)$ & $179(34.8)$ & \\
\hline $6-10$ & $163(31.7)$ & $162(31.5)$ & \\
\hline$>10$ & $174(33.9)$ & $173(33.7)$ & \\
\hline Mean (SD) & $8.8(5.4)$ & $8.8(5.4)$ & \\
\hline Previous treatment for infertility & & & $<0.0001(14.7,1)$ \\
\hline No & $343(67)$ & $283(55)$ & \\
\hline Yes & $171(33)$ & $231(45)$ & \\
\hline Causes of infertility & & & $0.85(0.78,3)$ \\
\hline Female factor & III (2I.6) & $122(23.7)$ & \\
\hline Male factor & $292(56.8)$ & $286(55.6)$ & \\
\hline Both (male \& female factor) & $43(8.4)$ & $39(7.6)$ & \\
\hline Unexplained & $68(13.2)$ & $67(13.0)$ & \\
\hline
\end{tabular}

ences on 3 measures (physical functioning, social functioning and mental health).

Finally, to indicate independent effects of variables studied, logistic regression analysis was preformed. Table 4 indicates the results. Overall, younger age, female gender and lower level of education were found to be significant predictors of poorer health-related quality of life whereas duration of infertility, previous treatment for infertility or causes of infertility were not.

\section{Discussion}

This study investigated health-related quality of life of a large group of men and women planning to undergo IVF or ICSI treatment using the SF-36 questionnaire. The SF36 scores were markedly lower in females as compared to males. The study reported by Ragni et al. also showed similar results for infertile Italian couples where men scored higher than woman on the SF-36 [12]. Several studies have suggested that the impact of infertility and its treatment is higher in women than men and also clearly demonstrated that having children was more important to

Table 2: The SF-36 scores by gender

\begin{tabular}{llllll}
\hline & Male $(\mathrm{n}=5 \mid 4)$ & Female $(\mathrm{n}=5 \mid 4)$ & P* & Normative data for males** & Normative data for females** \\
\hline & Mean (SD) & Mean (SD) & & Mean (SD) & Mean (SD) \\
\hline PF & $86.7(20.9)$ & $80.6(21.8)$ & $<0.0001$ & $87.8(19.0)$ & $82.9(22.1)$ \\
RP & $78.3(31.0)$ & $72.0(33.3)$ & 0.002 & $73.8(36.4)$ & $66.5(39.1)$ \\
BP & $77.4(16.8)$ & $69.1(20.2)$ & $<0.0001$ & $82.7(23.4)$ & $76.4(26.2)$ \\
GH & $71.0(17.1)$ & $66.1(18.1)$ & $<0.0001$ & $70.2(19.6)$ & $65.0(20.8)$ \\
SF & $76.4(21.9)$ & $72.6(22.8)$ & 0.007 & $78.0(23.5)$ & $74.2(25.1)$ \\
RE & $73.0(35.6)$ & $65.4(38.6)$ & 0.001 & $70.1(39.7)$ & $61.4(42.4)$ \\
VT & $66.2(17.6)$ & $59.2(18.5)$ & $<0.0001$ & $68.9(16.2)$ & $62.9(17.8)$ \\
MH & $67.2(17.8)$ & $61.6(19.6)$ & $<0.0001$ & $69.2(17.1)$ & $65.0(18.6)$ \\
\hline
\end{tabular}

* Derived from two independent samples t-test.

** Data for the general population aged 15 and above [II].

PF: physical functioning, RP: role physical, BP: bodily pain, GH: general health, SF: social functioning, RE: role emotional, VT: vitality, MH: mental health. 
Table 3: The SF-36 scores by infertility causes ( 514 women and 514 men, higher scores indicate a better condition)

\begin{tabular}{|c|c|c|c|c|c|}
\hline & Female factor $(n=233)$ & Male factor $(n=578)$ & Both $(n=82)$ & Unexplained $(n=135)$ & P* \\
\hline & Mean (SD) & Mean (SD) & Mean (SD) & Mean (SD) & \\
\hline PF & $80.5(23.8)$ & $85.0(20.5)$ & $86.6(17.1)$ & $81.3(23.5)$ & 0.01 \\
\hline RP & $71.4(33.8)$ & $77.0(31.2)$ & $78.3(31.3)$ & $71.8(34.6)$ & 0.06 \\
\hline $\mathrm{BP}$ & $72.6(18.9)$ & $72.9(19.6)$ & $73.2(18.4)$ & $76.0(17.4)$ & 0.36 \\
\hline $\mathrm{GH}$ & $66.1(17.9)$ & $69.5(17.5)$ & $68.3(20.9)$ & $69.0(16.3)$ & 0.09 \\
\hline SF & $69.4(23.8)$ & $76.4(21.6)$ & $77.2(22.7)$ & $73.8(22.3)$ & 0.001 \\
\hline $\mathrm{RE}$ & $63.9(39.3)$ & $70.8(36.6)$ & $73.5(35.4)$ & $69.3(37.3)$ & 0.07 \\
\hline VT & $60.5(19.2)$ & $64.1(17.8)$ & $61.7(18.7)$ & $61.4(18.7)$ & 0.05 \\
\hline $\mathrm{MH}$ & $60.7(20.7)$ & $65.8(18.1)$ & $66.2(20.2)$ & $63.9(17.7)$ & 0.005 \\
\hline
\end{tabular}

* Derived from one-way analysis of variance (ANOVA)

PF: physical functioning, RP: role physical, BP: bodily pain, GH: general health, SF: social functioning, RE: role emotional, VT: vitality, MH: mental health.

women than men [6,13-17]. One reason for such findings is due to the fact that in general women usually rate their health-related quality of life lower than male gender. Another explanation is that women are blamed (or some times they take the blame) more frequently for the couple's infertility and thus, the stigma associated with such blaming (regardless of the diagnosis) causes more distress and deteriorations in health-related quality of life in female partners $[9,18]$. However, it should be noted that beyond general measures of health-related quality of life such as the SF, the scope of infertility and its effect on men might be different. For example, in a very recent study assessing sexual function and health-related quality of life in the male partner of infertile couples, Shindel et al. [19] reported that depression, erectile dysfunction and sexual relationship problems were prevalent among male partners of infertile couples and male partners reported significantly lower standardized scores on mental health compared to normative data. As suggested the evaluation of infertile women and men without comparing them to the general population contain several biases. Therefore it is recommended that when studying health-related quality of life in infertile couples it is better to include a control group to have a better understanding on the topic [12]. Unfortunately we were not able to provide such information and this requires a further investigation.

A study reported by Fekkes et al. showed that women planning IVF, in particular young women aged between 21-30 years, experienced more social and emotional problems than women of the same age group in the general population [6]. The present study also showed that younger age was a significant predictor for poorer mental health-related quality of life but not for physical healthrelated quality of life (see Table 4). It is argued that older patients have a longer history of infertility and thus might be able to cope with their medical situations in a better way because they have had more infertility-related experi- ences. However, it is argued that when the childlessness has become definite, psychological intervention should be continued to teach couples how to cope actively with their problems and how to ask for support in order to decrease the negative impact of their childlessness [20].

The study findings showed that lower educational level was a significant predictor of the poorer health-related quality of life, both physical and mental health. It is argued that certain socio-demographic characteristics of infertile women could be of importance in terms of perceived poorer health-related quality of life. For instance, it has been shown that highly educated infertile women would feel less stigmatized as compared to those with less education [9].

We also investigated the relationship between duration of infertility, causes of infertility and health-related quality of life. In univariate analysis we found that health-related quality of life was better in couples with male factor infertility or both male and female infertility factor (Table 3 ). However, the multivariate analysis showed that duration of infertility or causes of infertility were not significant predictors of poorer health-related quality of life (Table 4). As suggested these findings indicate that infertility might lead to similar experiences by all men and women, although they might explain themselves in different ways.

\section{Conclusion}

The study findings suggest that duration of infertility or causes of infertility do not have significant effects on health-related quality of life in infertile couples. However, infertile couples, especially less educated younger women, are at risk of a sub-optimal health-related quality of life and they should be provided help and support in order to improve their health-related quality of life. 
Table 4: Results of logistic regression analysis for poorer physical and mental health-related quality of life

\section{Adjusted OR $(95 \% \mathrm{Cl}) \quad \mathrm{P}$}

Physical component summary

Age groups (years)

\begin{tabular}{|c|c|c|}
\hline$>35$ & I.0 (ref.) & \\
\hline $31-35$ & $0.91(0.62-1.32)$ & 0.62 \\
\hline $25-30$ & $1.15(0.82-1.61)$ & 0.39 \\
\hline$<25$ & $1.24(0.67-2.26)$ & 0.48 \\
\hline \multicolumn{3}{|l|}{ Sex } \\
\hline Male & I.0 (ref.) & \\
\hline Female & $2.03(1.53-2.68)$ & $<0.0001$ \\
\hline \multicolumn{3}{|l|}{ Education } \\
\hline > 12 (higher) & I.0 (ref.) & \\
\hline 6-12 (secondary) & $1.40(1.02-1.93)$ & 0.03 \\
\hline$\leq 5$ (primary) & $\mathrm{I} .77(\mathrm{I} .25-2.5 \mathrm{I})$ & 0.001 \\
\hline \multicolumn{3}{|c|}{ Infertility duration (years) } \\
\hline$>10$ & I.0 (ref.) & \\
\hline $6-10$ & $0.93(0.65-1.33)$ & 0.71 \\
\hline$\leq 5$ & $1.16(0.84-1.6 I)$ & 0.34 \\
\hline \multicolumn{3}{|c|}{ Previous treatment for infertility } \\
\hline No & I.0 (ref.) & \\
\hline Yes & $1.06(0.81-1.39)$ & 0.67 \\
\hline \multicolumn{3}{|l|}{ Causes of infertility } \\
\hline Unexplained & 1.0 (ref.) & \\
\hline Female factor & $1.16(0.74-1.80)$ & 0.51 \\
\hline Male factor & $0.76(0.51-1.13)$ & 0.18 \\
\hline Both & $0.65(0.36-1.18)$ & 0.16 \\
\hline \multicolumn{3}{|c|}{ Mental component summary } \\
\hline \multicolumn{3}{|c|}{ Age groups (years) } \\
\hline$>35$ & I.0 (ref.) & \\
\hline $31-35$ & $1.22(0.85-1.76)$ & 0.28 \\
\hline $25-30$ & $1.46(1.05-2.03)$ & 0.02 \\
\hline$<25$ & $2.15(1.16-3.97)$ & 0.01 \\
\hline \multicolumn{3}{|l|}{ Sex } \\
\hline Male & I.0 (ref.) & \\
\hline Female & $1.4(1.07-1.85)$ & 0.01 \\
\hline \multicolumn{3}{|l|}{ Education } \\
\hline > 12 (higher) & I.0 (ref.) & \\
\hline 6-12 (secondary) & $1.68(1.19-2.36)$ & 0.003 \\
\hline$\leq 5($ primary $)$ & I.35 (0.98-I.84) & 0.06 \\
\hline \multicolumn{3}{|c|}{ Infertility duration (years) } \\
\hline$>10$ & 1.0 (ref.) & \\
\hline $6-10$ & $0.99(0.72-1.36)$ & 0.94 \\
\hline$\leq 5$ & $\mathrm{I} .10(0.77-1.57)$ & 0.60 \\
\hline \multicolumn{3}{|c|}{ Previous treatment for infertility } \\
\hline No & I.0 (ref.) & \\
\hline Yes & $1.22(0.93-1.58)$ & 0.15 \\
\hline \multicolumn{3}{|l|}{ Causes of infertility } \\
\hline Unexplained & I.0 (ref.) & \\
\hline Female factor & I.38 (0.89-2.14) & 0.14 \\
\hline Male factor & $0.87(0.59-1.29)$ & 0.51 \\
\hline Both & $0.70(0.39-1.24)$ & 0.22 \\
\hline
\end{tabular}

\section{Competing interests}

The authors declare that they have no competing interests.

\section{Authors' contributions}

$\mathrm{BR}$ was the main investigator and wrote the first draft. AM analyzed the data and wrote the final manuscript. FR, MS, and MA contributed to the study design, patient recruitments and helped to collect data. NA contributed to the data collection, data entry and coordinated the study. All authors read and approved the final manuscript.

\section{Acknowledgements}

We would like to thank the Vali-e-Asr Infertility Research Center and Royan Institute staff for their help and cooperation throughout the stages of the study. Also we would like to express our thanks towards the Deputy of Research and Head of Tehran University of Medical Sciences.

\section{References}

I. Leiblum SR, Greenfield DA: Infertility: psychological issues and counseling strategies. Edited by: Leiblum SR. New York: John Wiley \& Sons; 1997:83-102.

2. Fassino S, Piero A, Boggio S, Piccioni V, Garzaro L: Anxiety, depression and anger suppression in infertile couples. Hum Reprod 2002, 17:2986-2994.

3. Chen TH, Chang SP, Tsai CF, Juang KD: Prevalence of depressive and anxiety disorders in an assisted reproductive technique clinic. Hum Reprod 2004, 19:23 I3-23 I8.

4. van Balen F, Verdurmen J, Ketting E: Choices and motivations of infertile couples. Patient Educ Counsl 1997, 31:19-27.

5. Greil AL: Infertility and psychological distress: a critical review of the literature. Soc Sci Med 1997, 45:1679-1704.

6. Fekkes M, Buitendijk SE, Verrips GH, Braat DD, Brewaeys AM, Dolfing JG, Kortman M, Leerentveld RA, Macklon NS: Health-related quality of life in relation to gender and age in couples planning IVF treatment. Hum Reprod 2003, 18: 1536-1543.

7. Chachamovich JR, Chachamovich E, Zachia S, Knauth D, Passos EP: What variables predict generic and health-related quality of life in a sample of Brazilian women experiencing infertility? Hum Reprod 2007, 22:1946-1952.

8. Montazeri A: Infertility and health related quality of life: minireview of the literature. Journal of Family and Reproductive Health 2007, I:55-58.

9. Donkor ES, Sandall J: The impact of perceived stigma and mediating social factors on infertility-related stress among women seeking infertility treatment in Southern Ghana. Soc Sci Med 2007, 65:1683-1694.

10. Ware JE, Gandek B: Overview of the SF-36 Health Survey and the International Quality of Life Assessment (IQOLA) project. J Clin Epidemiol 1998, 5 I:903-12.

II. Montazeri A, Goshtasebi A, Vahdaninia M, Gandek B: Translation and validation study of the Iranian version of the Short Form Health Survey (SF-36). Qol Life Res 2005, 14:875-882.

12. Ragni G, Mosconi P, Baldini MP, Somigliana E, Vegetti W, Caliari I, Nicolosi AE: Health-related quality of life and need for IVF in 1000 Italian infertile couples. Hum Reprod 2005, 20: 1286-| $29 \mid$.

13. van Balen F, Trimbos-Kemper TC: Factors influencing the wellbeing of long-term infertile couples. J Psychosom Obstet Gynaecol 1994, I 15:157-164.

14. van Balen F, Trimbos-Kemper TC: Involuntarily childless couples: their desire to have children and their motives. J Psychosom Obstet Gynaecol 1995, 16:137-144.

15. Collins A, Freeman EW, Boxer AS, Tureck AR: Perceptions of infertility and treatment stress in females as compared with males entering in vitro fertilization treatment. Fertil Steril 1992, 57:350-356.

16. Odden BJ, Den Tonkelaar I, Nieuwnhuyse H: Psychosocial experiences in women facing fertility problems: a comparative survey. Hum Reprod 1999, 14:255-261. 
17. Pasch LA, Dunkel-Schetter C, Christensen A: Differences between husbands, and wives, approach to infertility affect marital communication and adjustment. Fertil Steril 2002, 77:124I-1247.

18. Peronace LA, Boivin J, Schmidt L: Pattern of suffering and social interactions in infertile men: 12 months after unsuccessful treatment. J Psychosom Obstet Gynecol 2007, 28: I05-I I4.

19. Shindel AW, Nelson CJ, Naughton CK, Ohebshalom M, Mulhall JP: Sexual function and quality of life in the male partner of infertile couples: prevalence and correlates of dysfunction. J Urol 2008, 179:1056-1059.

20. Lechner L, Bolman C, van Dalen A: Definite involuntary childlessness: associations between coping, social support and psychological distress. Hum Reprod 2007, 22:288-294.

\section{Pre-publication history}

The pre-publication history for this paper can be accessed here:

http://www.biomedcentral.com/1472-6963/8/186/pre

pub

Publish with Bio Med Central and every scientist can read your work free of charge

"BioMed Central will be the most significant development for disseminating the results of biomedical research in our lifetime. "

Sir Paul Nurse, Cancer Research UK

Your research papers will be:

- available free of charge to the entire biomedical community

- peer reviewed and published immediately upon acceptance

- cited in PubMed and archived on PubMed Central

- yours - you keep the copyright 